\title{
EUROPA EN CRISIS: EL DESENCANTO DE LA UNIÓN EUROPEA ${ }^{1}$
}

\author{
Stella Maris Shmite y María Cristina Nin ${ }^{2}$ \\ Universidad Nacional de La Pampa \\ (Argentina)
}

\section{RESUMEN}

Las desigualdades y las tensiones sociales se manifiestan territorialmente en las ciudades europeas, las que se constituyen en espacios estratégicos donde se materializan las reivindicaciones sociales. La combinación del proceso de globalización y la organización institucional supranacional de Europa, junto a las profundas transformaciones que afectan la economía y por lo tanto, al sistema social característico del Estado de Bienestar, conducen a la emergencia de sentimientos de insatisfacción e incertidumbre que se expresan en los movimientos sociales. En este artículo se aborda el rol de la Unión Europea frente a la crisis, las respuestas institucionales, las consecuencias económicas y sociales y la emergencia de un cuestionamiento de la sociedad al funcionamiento de los Estados y la estructura supranacional.

Palabras clave: Geografía, Unión Europea, crisis, movimientos sociales.

\section{EUROPE IN CRISIS: THE EUROPEAN UNION DISILLUSIONMENT}

\begin{abstract}
Social inequalities and tensions are currently observed in the territories of the European cities, which constitute strategical spaces where social claims are materialized. The combination of globalization processes and Europe's supranational institutional organization, together with the deep transformations which affect the economy and, as a result, the characteristic social system of the Welfare State, have led to the emergence of feelings of dissatisfaction and
\end{abstract}

Fecha de recepción: 11 de Junio de 2014. Fecha de aceptación: 25 de Noviembre de 2014.

1 Este artículo pertenece al Proyecto «Territorios dinámicos, tramas complejas. Deconstruyendo las relaciones de poder, los actores y las tensiones en diferentes escalas» en el marco del Programa de Investigación «Contextos territoriales contemporáneos: abordajes desde la geografía», aprobado por Resolución N 093-14 -CD-FCH-UNLPam. Facultad de Ciencias Humanas.

2 Gil 353, Santa Rosa (6.300), La Pampa,_Argentina.shmite_stella@yahoo.com.ar y ninmcristina@gmail.com 
uncertainty expressed by social movements. This article focuses on the role of the European Union vis-á-vis the crisis, the institutional answers, the socio-economic consequences, and the emergence of social demands to the States and the supranational structure.

Key words: Geography, European Union, crisis, social movements.

\section{INTRODUCCIÓN}

«Es una sociedad de trabajadores que se va a liberar de las cadenas del trabajo, y esta sociedad ya no sabe nada de las actividades más altas y más enriquecedoras para las que valdría la pena obtener esa libertad... Lo que tenemos ante nosotros es la perspectiva de una sociedad de trabajadores sin trabajo, es decir, privados de la única actividad que les queda. No es posible imaginar nada peor.» ARENDT, Hannah en GORZ, Andre 1997: 19.

En el contexto europeo actual existen ciertos factores que explican la crisis de legitimidad de las instituciones, tales como la transformación de la soberanía estatal en el marco de las múltiples instituciones y organismos supraestatales, así como los cambios en la configuración comunitaria impulsados por el proceso de globalización. En el caso de la soberanía estatal, ésta se ejerce actualmente en el contexto de la Unión Europea y por tanto, en un marco jurídico-institucional que está por encima de las fronteras nacionales. Sumado a esto, la globalización económica contemporánea ha impuesto además formas de control y ejercicio de la soberanía económica, por ejemplo, a través del Banco Central Europeo y el Euro como moneda única. Estos factores transforman el sentir y el pensar de Europa respecto a su propia identidad y a la identidad territorial (ALSAYYAD y CASTELLS, 2003).

Los países europeos, y particularmente los miembros de la Eurozona, transitan por una recesión económica sostenida desde la crisis de 2007-2008. Se trata de la contracción económica más larga desde la creación de la moneda única. Sin embargo, la crisis no es solo financiera, es una crisis general que desestabiliza los cimientos de la Unión Europea. Las promesas de igualdad y acceso al trabajo que se diseñaron en la Europa comunitaria, así como otros beneficios propios del Estado de Bienestar, se están desmantelando. En medio de estos procesos surgen movimientos sociales que manifiestan el malestar y resisten al avance del capitalismo financiero.

La crisis financiera puede pensarse como coyuntural, pero la crisis de Europa es estructural. Las asimetrías entre economías centrales y periféricas dentro de la Unión Europea se agravaron en los últimos años y la solución quedó librada al mercado, que demostró su incapacidad para resolver los desequilibrios sociales, económicos, políticos y culturales. Los ciudadanos de los países considerados periféricos como Grecia, Italia, España, Portugal o Irlanda son los más afectados, pero esto parece ser sólo el inicio. Las protestas irrumpen el orden político-económico de la Unión Europea y los síntomas de la crisis se evidencian en todos los países. 
El propósito de este artículo es interpretar la crisis actual para comprender un tema complejo de la sociedad contemporánea, la geografía de las desigualdades. El abordaje de una problemática actual como la crisis de Europa requiere del análisis y selección de múltiples fuentes de información, diversos autores y cruces teórico-metodológicos con el fin de enriquecer la enseñanza de esta temática en el aula universitaria.

\section{CRISIS DEL ESTADO DE BIENESTAR}

El Estado de Bienestar y el Modelo Social Europeo son dos rasgos que caracterizan la imagen de Europa en el mundo. Existen múltiples conceptos que definen el Modelo Social Europeo, pero todos confluyen en el Estado de Bienestar, que fundamentalmente se caracteriza por tener: un Estado desarrollado e intervencionista financiado a través de impuestos elevados; un sistema de bienestar que proporciona protección social a todos los ciudadanos, y especialmente a los más necesitados; una limitación o contención de las desigualdades sociales y económicas (GIDDENS, 2007).

Todas estas características se sostienen en base al respeto de los derechos de los trabajadores, siempre vinculadas con una prosperidad económica en aumento y una situación de pleno empleo. Este contexto garantiza los derechos de ciudadanía de contenido social y económico para toda la población.

A pesar de la crisis actual, a la Unión Europea se le deben reconocer logros importantes: la reconciliación y acercamiento con países que estuvieron enfrentados (Europa Centro-Oriental); la construcción de democracias estables en todos los países miembros y el nivel de vida elevado, anhelado por los habitantes de otras regiones del mundo. Con veintiocho Estados, la Unión Europea es una de las regiones más dinámicas desde la perspectiva económica, y resulta atractiva para los ciudadanos de otros países de Europa del Este tales como los nuevos Estados surgidos de la ex Yugoslavia, Ucrania, e incluso Turquía. Asimismo, para ciudadanos de otros países del mundo.

En el contexto de la crisis actual, las conquistas sociales del Estado de Bienestar comenzaron a debilitarse. Los datos estadísticos muestran el aumento de las tasas de desempleo en los últimos cinco años: España pasó de 2.586.600 desocupados en 2008 a 6.202.700 en 2013; Grecia pasó de 377.200 desempleados en 2008 a 1.320 .000 en 2013 lo que representa aproximadamente un $27 \%$ de la población desempleada en ambos países. Esta situación está representada en el Mapa № 1 (EUROSTAT 2013).

De acuerdo al análisis de Ulrich Beck, la crisis no solo debe interpretarse desde la perspectiva económica, sino también desde una mirada socio-cultural. Tal como sostiene este autor, «(...) sin los valores de la libertad y la democracia, sin sus orígenes culturales, Europa no es nada» (BECK 2012: 36).

Las condiciones cambiantes del mercado de trabajo en Europa son actualmente la principal fuente de incertidumbre e inseguridad para los ciudadanos. Los Estados europeos contemporáneos no pueden sostener el modelo y seguir cumpliendo la consigna de pleno empleo que caracterizó al Modelo Social Europeo en las décadas anteriores. 
MAPA 1

El desempleo en la Unión Europea - Enero 2013.

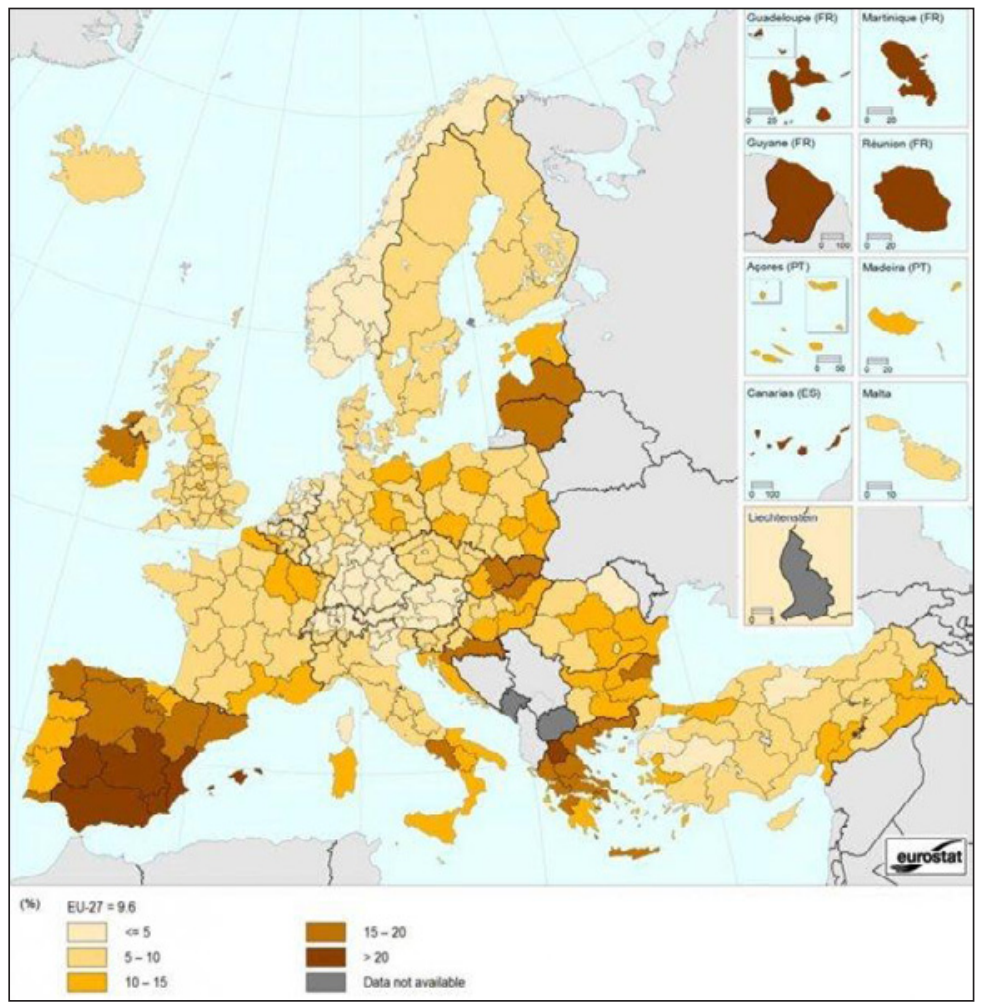

Fuente: EUROSTAT 2013.

\section{CRISIS ECONÓMICO-FINANCIERA}

La crisis del endeudamiento de los países de la Unión Europea, en el contexto de la crisis financiera global del 2008, expresa la carencia de un gobierno democrático europeo que tenga competencias frente a la banca trasnacional y frente a los mercados financieros internacionales. La Unión Europea no tiene fronteras para los movimientos de capitales y los gobiernos están impedidos de restringir estas transacciones. Los bancos centrales de los países europeos no pueden controlar los movimientos de capitales ni las operaciones trasnacionales que realizan las filiales de los bancos. El conjunto de los veintiocho países de la Unión Europea están bajo un complejo sistema de organismos supranacionales, vinculados con los grandes bancos y corporaciones globales que funcionan en el contexto de la globalización financiera.

«La mundialización financiera ha creado de esta forma su propio Estado. Un Estado supranacional, que dispone de sus aparatos, de sus redes de influencia 
y de sus propios medios de acción. Se trata de la Constelación formada por el Fondo Monetario Internacional ( FMI), el Banco Mundial (BM), la Organización para la Cooperación y Desarrollo Económico (OCDE) y la Organización Mundial del Comercio (OMC)» (RAMONET, 2008: 53).

Este «Estado mundial» configurado financieramente, no se vincula con la sociedad dado que el poder es ejercido por los mercados financieros y las grandes empresas transnacionales. En este contexto, las sociedades tienen cada vez menos poder de participación en las decisiones políticas del Estado nacional (RAMONET, 2008). La principal deficiencia del sistema monetario de la Unión Europea radica en que es un territorio de dimensiones continentales y con una población que supera los 500 millones. (EUROSTAT, 2013), «(...) se creó un mercado común con una moneda parcialmente común sin que por otra parte se diesen pasos hacia una verdadera unión económico-política (razón por la que no es posible coordinar eficazmente las economías de los estados de la zona euro)» (BECK, 2012: 24).

De acuerdo con Harvey (2013) la creación del euro fue una operación que benefició a la clase capitalista, y en particular a los sectores más desarrollados de los países económicamente más dinámicos de la Unión Europea. Por lo tanto, la creación del Euro se puso en marcha en un espacio común pero con desigualdades internas, donde algunos países se beneficiaron (Alemania) mientras que otros no tanto, como es el caso de Grecia entre los países del sur.

Los problemas financieros de cada Estado tienen que ser resueltos en concordancia con las políticas comunes, esto fue factible en décadas anteriores en situaciones de estabilidad económica y financiera, pero esta articulación es difícil de sostener en tiempos de crisis. Los hechos económicos y financieros que atraviesa la Unión Europea desde 2008 demuestran la estrecha interrelación existente entre las políticas estatales y las acciones económico-financieras comunes.

\section{ASIMETRÍAS EN EL INTERIOR DE LA UNIÓN EUROPEA}

A partir de la ampliación del bloque europeo en 1986 con la incorporación de Grecia, España y Portugal, el producto bruto interno por habitante del Estado más rico era 4,9 veces superior al del Estado más pobre. Esta diferencia pasó a 20,1 veces en 2007 con la incorporación de Rumania, Bulgaria y Croacia. Con las últimas ampliaciones se integró al espacio común europeo a países con un nivel de desarrollo inferior a la media comunitaria. Pero también es necesario tener en cuenta que son dos épocas diferentes en el contexto internacional y por lo tanto, las variables políticas y económicas son muy disímiles.

En las últimas décadas la distribución del presupuesto de la Unión Europea cambió notablemente. Se estableció en aproximadamente el 1\% del PIB comunitario desde 1999 hasta 2013. El resultado fue que los campesinos de Europa del Este no tuvieron acceso a las mismas ayudas económicas que los países del sur cuando se incorporaron en 1986. Por otra parte, a partir de 2013, se aplican a todos los países las mismas reglas de concesión de fondos, por lo tanto una importante proporción de los fondos europeos no sería accesible para las regiones más pobres (EUROSTAT 2013). 
«Resulta evidente que los gobiernos democráticos y de la UE han fracasado en la reforma del sistema que llevó a la gran crisis; y de nuevo los mercados financieros globales muestran su pujanza sin interferencias de los Estados, a los que imponen sus criterios y amparados por los entes que denominamos los reguladores privados en la sombra reforzados después de la gran crisis, como son las agencias privadas de calificación de riesgos crediticios, el Consejo de Normas Internacionales de Contabilidad (IASB, en siglas inglesas), el legislador mundial de la contabilidad financiera y el BIS, el Banco de Pagos Internacionales de Basilea (Suiza) que fija las normas bancarias» (HERNÁNDEZ VIGUERAS, 2012: 338-339).

La debilidad del presupuesto de la Unión Europea, agravado por las políticas económicas implementadas por los Estados en el contexto neoliberal, provocó la profundización de las diferencias sociales y regionales. La necesidad de aplicar con rigor la gestión del presupuesto comunitario se tradujo en la reducción del gasto social y el aumento de los impuestos. Los nuevos Estados miembros de la Europa del Este respetaron los criterios impuestos por los países miembros de la Zona Euro (antiguos integrantes) y las diferencias económicas y las desigualdades sociales se incrementaron a partir del año 2000. En este contexto, los salarios decayeron y la inflación aumentó, al igual que la desregulación del mercado de trabajo.

\section{INCERTIDUMBRE, MALESTAR Y PRECARIEDAD LABORAL}

Las protecciones sociales propias del Modelo Social Europeo se han deteriorado progresivamente en los últimos años del siglo XX y el Estado ya no tiene capacidad para afrontar las demandas sociales, y no puede sostener las políticas sociales y económicas que garantizaban una vida cotidiana segura para dar paso a la incertidumbre, fragilidad y malestar social. Estas expresiones de los sujetos sociales se traducen en miedos individuales como inseguridad, incertidumbre y desprotección, según expresiones de Bauman (2003).

En relación con las políticas de empleo, en el seno de la Unión Europea se percibe la tensión entre los gobiernos nacionales y las decisiones de la Comisión Europea. Mientras que los primeros adoptan estrategias de integración a la globalización liberal y otorgan poder a la Unión Europea para resolver el problema de la precarización laboral, las medidas propuestas por la Comisión resultan insuficientes. Los reclamos sociales demandan una política de empleo a largo plazo, especialmente para los jóvenes, medidas que requieren inversión educativa y reajustes económicos. En este contexto cabe preguntarse: ¿los Estados están dispuestos a emprender estos desafíos? ¿Han recibido los jóvenes suficiente formación para afrontar los mercados actuales?

En momentos en que se flexibiliza y desestructura el sistema laboral europeo, emergen nuevos movimientos sociales que se solidarizan con los desempleados y con los jóvenes que no encuentran trabajo. La incertidumbre y el malestar de la población económicamente activa se expresa territorialmente y se visibiliza en los espacios públicos de las ciudades europeas, pero el proceso es complejo, multivariable y heterogéneo. 
La polarización de la sociedad europea, anticipada por Rifkin (1996), se ha incrementado y actualmente, se puede diferenciar por un lado, una elite bien formada que controla y gestiona la economía global de alta tecnología, y por otro lado, un creciente número de trabajadores desempleados con pocas posibilidades de conseguir empleo, en un mundo cada vez más automatizado. A medida que la tercera revolución industrial se abre paso en todos los sectores productivos, se acrecienta el aumento de trabajadores insertos en situación de inseguridad laboral. El sociólogo Ulrich Beck manifiesta que:

«(...) no se trata de la desaparición del trabajo de la sociedad laboral ni tampoco del fin del trabajo asalariado, sino pura y simplemente del final de la sociedad del pleno empleo. Una tasa de desempleo del $2 \%$, cobertura social para cada puesto de trabajo, una relación laboral normal por regla general... ¿Se puede decir que todo esto es ya historia? La controversia fundamental gira, pues, en torno a esta pregunta ¿Restablecimiento o fin de la sociedad del pleno empleo?» (BECK, 2000:45).

La restructuración que ha sufrido el mercado laboral enmarcada en la volatilidad del mercado, la mayor competencia, la disminución de las ganancias y la debilidad de los sindicatos, ha desembarcado en contratos laborales muchos más flexibles. Acerca de las condiciones de la flexibilidad laboral, Harvey expresa,

«Es difícil hacerse un cuadro global, porque el propósito mismo de esta flexibilidad es satisfacer las necesidades a menudo muy específicas de cada firma. Hasta para los empleados regulares, son cada vez más comunes los sistemas como la «quincena de nueve días», o los horarios de trabajo que promedian una semana de cuarenta horas al año pero que obligan al empleado a trabajar mucho más en los momentos de los pocos de demanda y a compensar con horas más cortas en períodos de poca actividad. Pero más importante ha sido el desplazamiento del empleo regular hacia los contratos o subcontratos de trabajo temporario o de medio tiempo» (HARVEY, 2008:173).

Se pueden considerar diferentes dimensiones de la precariedad laboral dentro de la sociedad actual. Entre ellas podemos encontrar: la privatización de los servicios públicos como el sector de energía y telecomunicaciones; la aceleración de la producción y acumulación de riqueza en algunos sectores de la sociedad; la reestructuración radical del mercado laboral; la debilidad del poder sindical; la tecnología, entre otros. En este sentido, Lyotard afirmaba a inicios de la década de 1990 que el «(...) redespliegue económico en la fase actual del capitalismo, ayudado por la mutación de técnicas y tecnologías, marcha a la par, ya se ha dicho, con un cambio de función de los Estados» (LYOTARD, 1991: 15), y efectivamente, en la actualidad los Estados están imposibilitados de gestionar el mercado laboral. Éste se rige por las normas y demandas de las empresas. En palabras de André Gorz ${ }^{3}$,

3 El filósofo André Gorz publicó en 1990 en Le Monde Diplomatique una crítica a la ideología del trabajo contemporáneo. Un extracto de este artículo es reproducido en Le Monde Diplomatique N 167, mayo de 2013. 
«Ahora, la identificación con el trabajo es imposible, ya que el sistema económico no necesita -o no necesita de modelo habitual- su capacidad laboral. La exaltación del «recurso humano» oculta la realidad de que el empleo estable, de tiempo completo durante todo el año y a lo largo de toda la vida activa, se está convirtiendo en el privilegio de una minoría. Para los demás, el trabajo deja de ser un oficio que integra a la comunidad productiva y define un lugar en la sociedad. Lo que el empresario llama «flexibilidad» se traduce para los trabajadores en precariedad [...]» (GORZ, 2013:27).

La Unión Europea se fundamenta en tres pilares fundamentales ratificados por el Pacto de Estabilidad de 1997 y sancionados por el Banco Central Europeo: estabilidad de los precios, equilibrio presupuestario y estímulo de la competencia. Ninguno de estos pilares garantiza la defensa del Modelo Social Europeo, o la reducción del desempleo o el estímulo al crecimiento económico.

\section{DESIGUALDADES Y EMERGENCIA DE MOVIMIENTOS SOCIALES}

Tal como afirma Méndez (2011), las ciudades son protagonistas destacadas de la crisis actual, debido a que se localizan en ellas sus principales manifestaciones. Espacios contradictorios y paradójicos, en las ciudades se expresan las confrontaciones de los intereses de múltiples actores públicos y privados.

«En ámbitos como el europeo, las ciudades son espacios estratégicos para la evolución de unas sociedades altamente urbanizadas desde hace décadas. En ellas -particularmente en las principales metrópolis - se concentran las empresas, el conocimiento y el capital humano, surgen y se desarrollan buena parte de las innovaciones tecnológicas organizativas y sociales, se localizan los principales centros de poder político, económico o mediático, así como las élites que lo detentan, principales protagonistas del proceso de globalización» (MÉNDEZ, 2011:6).

Es así que en el espacio de las ciudades las resistencias locales se manifiestan y toman forma. En el caso europeo, se manifiestan contra el sistema e instituciones que no están respondiendo a los intereses democráticos que los ciudadanos pretenden. Los Estados europeos, con sus políticas neoliberales, revelan que están cada vez más alejados de los ciudadanos. Es posible que la incertidumbre generada a partir de la crisis actual estimule la búsqueda de soluciones, las cuales deberán estar enmarcadas en la democracia plena y en el respeto de los derechos ciudadanos, pero el camino aún no está marcado.

«Las actuales movilizaciones son el resultado de un lento proceso donde se reúnen fuerzas y experiencias. Cuando se reivindica democracia, libertad y justicia, y se protesta contra la corrupción de los partidos políticos, el poder omnímodo de banqueros, el capital financiero, las políticas de ajuste, el paro juvenil, el sistema electoral, la privatización de la salud, la enseñanza o el ca- 
lentamiento global se desnudan sistemas políticos donde prima la injusticia, la desigualdad y la explotación. En estas reivindicaciones hay historia, un largo recorrido que han recorrido los movimientos sociales ciudadanos en las luchas políticas y sociales» (ROITMAN ROSENMANN, 2012:45).

En este sentido, Bauman (2009) sostiene que existe un sentimiento generalizado de inestabilidad social e individual. Para describir esta situación de enorme complejidad, el autor utiliza tres palabras: incertidumbre, inseguridad y vulnerabilidad, aunque también se podría definir como «precariedad». Esta situación, en el contexto del sistema capitalista actual, produce una fractura social y política que está afectando a la Unión Europea y como consecuencia, surgen las protestas sociales. La vulnerabilidad del Estado se hace visible en el interior de esta unidad supranacional y tiene que ver con el grado de confianza que los ciudadanos depositaron en las instituciones y que hoy no responde a sus espectativas.

El Estado de Bienestar o «Estado Social» como Bauman (2009) prefiere denominarlo, es la culminación de una larga historia de democracia en Europa que hoy aparece debilitada. El Estado de Bienestar implicaba la defensa de los ciudadanos y aseguraba su inclusión e integración social. La competencia del mercado y las condiciones laborales actuales son una fuente de incertidumbre e inseguridad que los afecta. El Estado actual es cada vez menos capaz de prometer seguridad a los ciudadanos, y está cada vez menos dispuesto a hacerlo. Los trabajadores más vulnerables se localizan en los territorios más vulnerables. Esto es así porque se produjo un desarrollo geográfico desigual de la crisis.

Tal como afirma Castells, los «(...) movimientos sociales contra la crisis, en sus distintas formas, son los que están operando la transición en Europa entre una democracia liberal agotada en sus formas y procesos y una nueva democracia todavía por descubrir» (CASTELLS, 2013:49). Los ciudadanos europeos protestan en contra de la responsabilidad de las instituciones financieras en aplicar modelos especulativos de crecimiento y provocar el endeudamiento de los países, las empresas y las familias, en la protección que han brindado los gobiernos a los bancos para lograr su rescate ante situaciones que tienen como principal consecuencia el aumento del desempleo y la desarticulación de los servicios sociales.

El sur de Europa es sin dudas donde el movimiento social se puede considerar más poderoso. Se evidencian diferencias territoriales al interior de la UE, no todos los países de la Euro Zona respondieron de igual modo frente a la crisis. Para Harvey (2013), esta situación de crisis social y económica, que no sólo se manifiesta en Europa sino en otras regiones del mundo, tiene en el fondo una cuota de esperanza.

«El movimiento de los indignados en España y Grecia, los impulsos revolucionarios en Asia, todos ellos están comenzando a ver a través de la vasta bruma con la que un capitalismo global depredador y montaraz ha cubierto el mundo. ¿Qué hará falta para que el resto de nosotros lo perciba y actúe en consecuencia? ¿Cómo podemos recomenzar más eficaz y satisfactoriamente? ¿Qué dirección debemos tomar? las respuestas no son fáciles, pero algo sabemos con seguridad: que solo podemos llegar a las respuestas acertadas haciendo las preguntas acertadas.» (HARVEY, 2013:227). 
Los ciudadanos sufren penurias en Grecia a causa de la política de austeridad impuesta por el poder político económico capitalista, cuyos interesen principales están localizados en Alemania y el norte de Europa. Esta geografía desigual de la crisis no cambiará en el corto plazo (HARVEY, 2013) y también existen diferencias entre las distintas expresiones de protestas, según sostiene Étienne Balibar,
«(...) por ahora, sin embargo, los movimientos sociales a menudo operan con una perspectiva nacional. Los únicos que se han planteado el problema de construir un espacio público europeo de acción política han sido los indignados españoles, que exigen tanto poner fin a la dictadura de los mercados como la necesaria democratización de la vida pública. (...) Los indignados españoles son sin dudas un movimiento social. Tienen sus raíces en el territorio, han desarro- llado sus propias instituciones, han definido reglas para la toma de decisiones y, por último, han planteado con fuerza el nudo de las relaciones sociales de producción» (BALIBAR, 2011: 3).

El movimiento «Indignados» ${ }^{4}$ comenzó siendo una manifestación periférica basada en dos principios básicos: «Democracia Real Ya» y «Juventud sin Futuro». Los ciudadanos sin trabajo, sin casa, sin miedo, se dieron cita en las calles de Madrid, un domingo 15 de mayo de 2011 como un protesta espontánea convocada a través de las redes sociales y terminó en grandes acampadas en las principales plazas de varias ciudades españolas. En Madrid, Barcelona, Valencia, Pamplona, Sevilla, Bilbao, entre otras, las plazas fueron ocupadas y se convirtieron en la expresión territorial de la indignación de los ciudadanos. La «Puerta del Sol» en Madrid se convirtió en símbolo de resistencia» (ROITMAN ROSENMANN, 2012).

Este movimiento facilitó la construcción de un espacio híbrido entre lo virtual y el espacio público real, sin un líder pero mediante una organización democrática de asambleas en las que se discuten las ideas y los reclamos que circulan en las redes. «(...) los movimientos sociales tienen que labrarse un nuevo espacio público que no se limite a Internet sino que se haga visible en los lugares donde se desarrolla la vida social» (CASTELLS, 2012:27). Por esta razón, los ciudadanos ocupan espacios de valor simbólico (plazas y/o edificios) que representan un rol destacado en el proceso histórico de construcción urbana a escala local.

Este proceso demuestra la insatisfacción social hacia la moneda única y hacia la propia Unión Europea. «Por ahora la legitima protesta de los ciudadanos se focaliza contra sus propios gobernantes, complacientes marionetas de los mercados. ¿Qué pasará cuando se decidan a concentrar su ira contra el verdadero cuartel general, o sea, la propia UE» (RAMONET, 2001:25).

4 Esta denominación se inspiró en el libro «indígnate! Un alegato contra la indiferencia y a favor de la insurrección pacífica» escrito por Stéphane Hessel, editado en 2011, miembro de la Resistencia francesa y el único redactor vivo, en ese momento, de la Declaración Universal de los Derechos Humanos de 1948. El autor convoca a realizar un movimiento pacífico, a revelarse a perder la actitud de indiferencia para comprometerse con las causas sociales y salvar los valores democráticos. 


\section{EL ROL DE LAS EMOCIONES EN LOS MOVIMIENTOS SOCIALES}

Tal como expresa Moisi (2009), las emociones reflejan el grado de confianza de una sociedad en sí misma y en las instituciones, y por su parte, esto determina la capacidad de una sociedad para recuperarse de una crisis, responder a los nuevos desafíos y adaptarse a contextos cambiantes. «Pero la actual desilusión frente a las democracias occidentales es nueva, dolorosamente real y creciente. [...] Creo que existe una conexión entre el miedo que sentimos y el debilitamiento del ideal democrático» (MOISI, 2009: 144). Es evidente que en el contexto actual, las democracias europeas dejaron de lado los valores e ideales ciudadanos que constituyeron la base de su atracción.

A partir de los años '90, los problemas económicos se acrecentaron en los distintos Estados de la Unión Europea. Para los ciudadanos, los problemas financieros, incluso los problemas cotidianos se convirtieron en sensaciones que expresaban el miedo al fin del Estado de Bienestar. Esta sensación de miedo se reforzó con el temor a la pérdida de empleo frente a los inmigrantes, situación que en algunos países como Francia o Alemania se evidenció con acciones xenófobas. En este sentido, Castells expresa que,

«Si los orígenes de los movimientos sociales se encuentran en las emociones de los individuos y en sus interconexiones a partir de la empatía cognitiva, ¿Cuál es el papel de las ideas, ideologías y propuestas programáticas consideradas tradicionalmente como la materia de la que está hecho el cambio social? En realidad son materiales indispensables para el paso de la acción impulsada por las emociones a la deliberación y la construcción de proyectos. (...) Cuanto más se generen ideas dentro del movimiento a partir de la experiencia de sus participantes, más representativo, entusiasta y prometedor será aquél, y viceversa» (CASTELLS, 2012: 32).

Las emociones personales se canalizaron en las manifestaciones sociales colectivas. Los sujetos sociales comenzaron a expresar en público los sentimientos que tenían guardados en su interior, producto de largos años de disconformidad con el Modelo Social Europeo. «Decir en voz alta y colectivamente lo que todos habían guardado durante años fue un gesto liberador que hizo el movimiento más expresivo que instrumental a corto plazo. Como sabemos las emociones impulsan la acción colectiva, esto podría ser de hecho clave para un futuro cambio social [...]» (CASTELLS, 2012: 138). Los movimientos sociales se originan por emociones derivadas de algún acontecimiento socioeconómico que impulsa las acciones colectivas que desafían al poder de las instituciones del Estado, a pesar del peligro que suponen sus acciones.

El sentimiento de fragilidad e inseguridad laboral se manifiesta especialmente entre los jóvenes con formación profesional universitaria, que intentan incorporarse al mercado laboral. Este malestar pasa de una generación a otra, a medida que los hijos de padres desempleados buscan empleo y tienen dificultades para conseguirlo. Parece ser el momento oportuno de reclamar para los jóvenes profesionales sin trabajo, para la población pasiva definitiva que ha visto recortados sus ingresos, y para los que están expuestos a los «daños colaterales» (BAUMAN, 2011) del sistema económico-financiero global. Todos 
los ciudadanos deben «(...) luchar juntos desde abajo no por menos Europa sino por una unión comprometida con principios políticos y socialdemócratas, pues solo esta estaría en situación de salir al paso eficazmente contra las causas de la miseria» (BECK, 2012:100). A pesar de la ausencia de un liderazgo fuerte, los movimientos sociales tuvieron la oportunidad de legitimar los reclamos, sin embargo, existe una contradicción entre el poder y la legitimidad. Los reclamos son indudablemente legítimos, pero no tienen poder. Por el contrario, las instituciones europeas tienen poder, pero son incapaces de legitimar los reclamos sociales, «(...) quizás podría formarse una coalición entre los movimientos de protesta y la vanguardia de los arquitectos de Europa con cuya fuerza dar el salto cuántico político que desemboque en la capacidad de actuar internacionalmente» (BECK, 2012: 101).

\section{REFLEXIONES FINALES}

El territorio supranacional constituido por la Unión Europea es un espacio político abierto, es un constructo social que está en un continuo proceso de transformación. Los movimientos sociales pusieron en evidencia el resurgimiento de la ciudad como espacio estratégico para entender las tendencias clave de la reconfiguración del orden social demandada por los ciudadanos europeos (SASSEN, 2007). En la problemática analizada en este artículo, las ciudades europeas se constituyen en los lugares donde se territorializan los acontecimientos macrosociales relevantes de la sociedad actual. Las ciudades conforman una instancia territorial en la que se construye una trama compleja de procesos que trascienden la escala nacional y regional, y adquieren una dimensión global. El debilitamiento de los Estados nacionales da lugar a la emergencia de nuevas formas de organización política, donde las ciudades adquieren un rol relevante y favorecen la materialización de los reclamos sociales, atravesados por diversas dimensiones: política, económica, social, cultural, ambiental.

La crisis de los países de la Unión Europea puso en evidencia el funcionamiento de la estructura supranacional, y la pérdida de poder de los Estados en forma individual. La crisis expresa las desigualdades territoriales y los límites de acción-decisión que los países de la periferia europea tienen para gestionar políticas que sostengan atributos del Modelo Social Europeo.

El desencanto de la sociedad civil europea a partir de la crisis económica de 2008, respecto a los derechos ciudadanos y la forma de gestión de la crisis, puso en tensión las decisiones de los Estados nación frente a las políticas aplicadas por la Unión Europea. En esta territorio supranacional coexisten dos lógicas: la lógica comunitaria y la lógica local. Para sostener y fortalecer el proyecto común, las instituciones de la Unión Europea tendrían que reconstruir las estructuras institucionales que respondan a las demandas de todos los ciudadanos por igual. La continuidad de la Europa supranacional debería complementarse con una mayor participación de la sociedad civil.

\section{BIBLIOGRAFÍA}

ALSAYYAD, N. y CASTELLS, M. (2003): ¿Europa musulmana o euro-islam? Política, cultura y ciudadanía en la era de la globalización. Alianza, Madrid, España. 
BALIBAR, É. (2011): Rebelión.org. «Si Europa fuese un contrapoder». 22/11/11. Fecha de consulta: 7/1/14. www.rebelion.org/noticia

BECK, U. (2000): Un nuevo mundo feliz. La precariedad del trabajo en la era de la globalización. Paidos, Barcelona.

BECK, U. (2012): Una Europa Alemana. Paidós, Buenos Aires.

BAUMAN, Z. (2003): En busca de la política. Fondo de Cultura Económica, Buenos Aires.

BAUMAN, Z. (2008): Archipiélago de excepciones. Katz, Madrid.

BAUMAN, Z. (2009): Múltiples culturas, una sola humanidad. Katz, Madrid.

BAUMAN, Z. (2011): Daños colaterales. Desigualdades sociales de la era global. Fondo de Cultura Económica, Buenos Aires.

CASTELLS, M. (2012): Redes de Indignación y Esperanza. Los Movimientos Sociales en la Era de Internet. Alianza, Madrid.

CASTELLS, M. (2013): Vanguardia. «Movimientos sociales contra la crisis». Número 46 Enero-Marzo 2013. La Vanguardia Ediciones, Barcelona.

ELATLAS IV. Mundos emergentes. Le Monde Diplomatique, Capital intelectual, Buenos Aires.

EUROSTAT. Estadísticas europeas. En www.eurostat.org

GIDDENS, A. (2007): Europa en la Era Global. Paidós, Barcelona.

GORZ, A. (1997): Metamorfosis del trabajo. Búsqueda del sentido Crítica de la razón económica. Editorial Sistema, Madrid.

GORZ, A. (2013) Le Monde Diplomatique. «Fin de la sociedad del trabajo. Nuevo empleo del tiempo» Número 167, mayo 2013.

HARVEY, D. (2008): La condición de la posmodernidad. Investigación sobre los orígenes del cambio cultural. Amorrortu editores, Buenos Aires.

HARVEY, D. (2013) «El Neoliberalismo como proyecto de clase» Entrevista publicada en la revista Contretemps. En www.contretemps.eu Fecha de consulta 15/12/2013.

HARVEY, D. (2013): Ciudades Rebeldes. Del derecho de la ciudad a la Revolución Urbana. Akal, Madrid.

HERNÁNDEZ VIGUERAS, J. (2012): El Casino que gobierna al Mundo. Mañas y trampas del Capitalismo Financiero. Capital Intelectual, Buenos Aires.

HESSEL, S. (2011): ¡Indígnate!. Destino, Buenos Aires.

HESSEL, S. y MORIN, E. (2013): El camino de la esperanza. Una llamada a la movilización pacífica. Destino, Paidós, Buenos Aires.

LYOTARD, J.F. (1991): La Condición postmoderna. Informe sobre el saber. Ediciones Cátedra, Madrid.

MÉNDEZ GUTIÉRREZ DEL VALLE, R. (2011): Las Escalas de la Crisis. Ciudades y Desempleo en España. Colección Estudios. Fundación $1^{\circ}$ de Mayo, Madrid.

MOISI, D. (2009): La Geopolítica de las Emociones. Grupo Editorial Norma, Bogotá.

MORIN, E. (2011): Cómo vivir en tiempos de crisis. Nueva Visión, Buenos Aires.

RAMONET, I. (2008): La Crisis del siglo. Globalización, especulación financiera, burbujas, capitalismo salvaje, crack. Capital Intelectual, Buenos Aires.

RAMONET, I. (2011): Le Monde Diplomatique. «Cambiar de Europa». N 146. Capital Intelectual, Buenos Aires.

RIFKIN, J. (1996): El fin del trabajo. Nuevas tecnologías contra puestos de trabajo: el nacimiento de una nueva era. Paidós, Barcelona. 
RIFKIN, J. (1998): Conferencia pronunciada en el Edificio Mercosur en Montevideo Uruguay. http://www.losrecursoshumanos.com/contenidos/4697-jeremy-rifkin-sabemosque-se-viene-el-tiempo-libre-mucho-tiempo-libre-la-pregunta-que-nos-planteamos-essi-va-a-ser-para Fecha de consulta: 14 de mayo de 2013.

ROITMAN ROSENMANN, M. (2012): Los Indignados. El rescate de la política. Editorial Akal, Madrid.

SASSEN, S. (2007): Una sociología de la globalización. Katz editores, Buenos Aires.

SASSEN, S. (2003): Los espectros de la globalización. Fondo de Cultura Economía, Buenos Aires. 